\title{
RENAL CLEARANCE OF EIGHTEEN INDIVIDUAL AMINO ACIDS IN HUMAN SUBJECTS ${ }^{1}$
}

\author{
By PAUL D. DOOLAN,2 HAROLD A. HARPER, MAXINE E. HUTCHIN, AND \\ WALTON W. SHREEVE ${ }^{3}$
}

(From the Metabolic Research Facility, U. S. Naval Hospital, Oakland, Calif.)

(Submitted for publication January 24, 1955 ; accepted April 6, 1955)

Studies of renal clearance of individual amino acids have been comparatively few in number. With the exception of those of Sheffner, Kirsner, and Palmer (1) such investigations have been performed solely on experimental animals and in certain respects the results which they have yielded have been conflicting. In part, the conflict has arisen because of the limited specificity of the analytical methods which the earlier investigators were forced to employ (2-7). Beyer and his associates (8-12), and Kamin and Handler (13), using the more specific methods of microbiological assay, were able to define these areas of conflict as well as to confirm and extend certain of the earlier findings. The most important findings of these previous investigations and the present state of knowledge on this subject might be summarized as follows:

1. In the fasting state the reabsorption of amino acids from the glomerular filtrate is almost complete.

2. When the filtered loads are increased, both the amounts of amino acid excreted and those which are reabsorbed are also increased.

3. Maximal reabsorptive capacities for amino acids, if attainable at all, are achieved by a mechanism different from that which governs the reabsorption of glucose.

4. There exists between certain individual and groups of amino acids a competition for reabsorption which is more obvious and aggressive than any such phenomenon which has heretofore been implied or demonstrated for other substances normally found in the tubular filtrate.

In view of the basic physiological importance

1 The opinions or assertions contained herein are the private ones of the authors and are not to be construed as official or reflecting the views of the Navy Department or the Naval Service at large.

2 Lieutenant, Medical Corps, United States Navy.

3 Present address: Brookhaven National Laboratory, Associated Universities, Inc, Upton, L. I., N. Y. of these findings and the interest demonstrated in recent years in various amino-acidurias, an investigation of the renal handling of individual amino acids by normal human subjects has been undertaken.

The proper utilization of a single amino acid depends on the simultaneous presence of a mixture of other amino acids in optimal concentrations; consequently, an attempt was made in these experiments to satisfy these requirements for amino acid utilization by infusing a solution which contained the eight amino acids shown by Rose (14) to be essential to the maintenance of nitrogen balance in normal human subjects. These "essential" amino acids were present in the same relative concentrations as suggested by Rose, and supplemental amounts of other amino acids were added to furnish additional nitrogen. During the infusion the clearances of 16 natural amino acids and 1 unnatural amino acid were measured. This approach to the problem requires the administration of a solution in which the individual amino acids are present in concentrations relative to one another that differ widely from those found in the plasma of fasting normal subjects. From this standpoint, the solution does not reproduce the usual circumstances under which the kidney deals with amino acids. To prepare a solution which would closely resemble normal plasma in the concentration of amino acids relative to one another is, however, not feasible because the sparingly soluble amino acids limit the amounts of the more soluble ones which could otherwise be used. It is recognized that an additional difficulty connected with the use of any mixture containing individual amino acids in different concentrations is that it makes comparison and interpretation of their renal clearances more difficult. This diffculty could be overcome by the infusion of a solution containing only one or possibly two amino acids but as has already been pointed out such an 
experiment may not be considered an entirely justifiable procedure from a physiological standpoint and at least with respect to lysine, arginine (11) and glycine (15), it has been shown that there is a quantitative difference in the renal excretion of these amino acids when infused alone, as compared to that which occurs when they are infused as a component of an amino acid mixture. In addition, it does not appear in any of the pathological conditions which have been studied that the renal reabsorptive defect is confined to a single amino acid (16). Infusions of single

TABLE I

Composition of infusion mixture

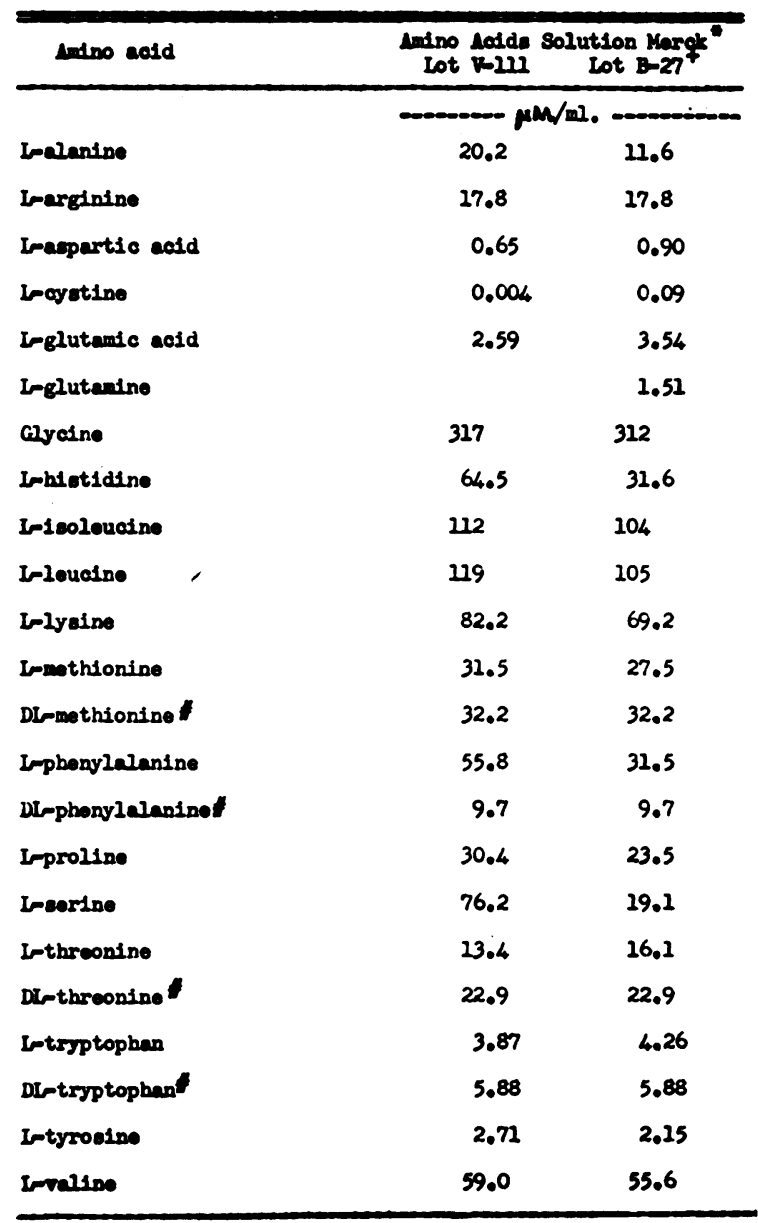

* The supplies of amino acids solution were generously provided by Merck \& Co., Inc.

+ The osmolarity of this solution was 978 milliosmols per liter.

\# Supplements to original amino acid solution as supplied by Merck. amino acids, although easier to work with, thus induce an element of artificiality which seriously limits any induction into clinical terms.

\section{METHODS}

Four clearance studies were performed in three normal individuals. Two were young, healthy Navy personnel-WB (wt. 150 lb., ht. 73 in., age 22) and DNW (wt. $190 \mathrm{lb}$., ht. 72.5 in., age 21). The other subject, WL (wt. $145 \mathrm{lb}$., ht. 67 in., age 60) had his left leg amputated years earlier. He originally volunteered to serve as a control for similar studies being performed on a 50-year-old nephrotic and since he was normal in all other respects, he is included in the present report.

Urine collection periods of 15 to $20 \mathrm{~min}$. were used. The bladder was rinsed with $15 \mathrm{ml}$. of saline followed by $15 \mathrm{ml}$. of air. In the first three clearances, urine flow rates during amino acid infusion of 3 to $4 \mathrm{ml}$. per min. were used because it was felt that excessive dilution might interfere with the amino acid analyses. Subsequently, it was found that the analyses were reproducible within a wide dilution range so that in later experiments, larger urine flows were maintained $(6$ to $12 \mathrm{ml}$. per min.). The glomerular filtration rate was measured by means of inulin clearance (17). The values given are uncorrected for surface area. After three control periods, $100 \mathrm{ml}$. of an amino acid mixture (Table I) were injected as a priming dose. A constant infusion of this solution was then started and after a 15-minute equilibration period, three more clearance periods were performed. In the first two studies the inulin and amino acid infusions were given at rates of 3 to $4 \mathrm{ml}$. per min. by means of a gravity drip. In the last two experiments, they were given at rates of 4.4 (WB) and 4.1 (DNW) ml. per min. by means of a constant infusion pump (Bowman).

The blood levels of the amino acids remained reasonably constant throughout the period of study but the variation in level obtained for any particular amino acid among different subjects was rather unpredictable. Since the individual amino acids are present in the infusion mixture in widely different concentrations (Table I) and are substances which are rapidly metabolized, the relative constancy in serum concentrations which were obtained was considered very satisfactory. Venous blood samples were taken at the midpoint of the control periods and at the beginning and end of each period during the infusion of both inulin and the amino acid solutions. No attempt at correction for renal dead space was made.

Seventeen natural amino acids were measured by microbiological assay using methods previously described (18). One unnatural amino acid, D-methionine, was measured by difference, using Lactobacillus fermenti to measure DL-methionine and Leuconostoc mesenteroides to measure L-methionine. Since the infusion mixture contains only free amino acids, only these forms were measured. No attempt was made to determine combined amino acids by comparison of values obtained before and 
TABLE II

Plasma concentration, filtered load and excretion values of the individual amino acids during a typical experiment on subject $W B$

\begin{tabular}{|c|c|c|c|c|c|c|c|c|c|c|c|c|c|}
\hline \multirow{4}{*}{$\frac{\text { Anino actids }}{\text { Inelanine }}$} & \multicolumn{5}{|c|}{ Pleuma coricentration } & \multicolumn{4}{|c|}{ Fillered loea } & \multicolumn{4}{|c|}{ Exaretion } \\
\hline & Fasting & \multicolumn{2}{|c|}{$\begin{array}{c}\text { Period of ter } \\
1\end{array}$} & \multicolumn{2}{|c|}{$\begin{array}{c}\text { loading } \\
3\end{array}$} & \multirow[t]{2}{*}{$\begin{array}{l}\text { Fasting } \\
(112)^{+} \\
\end{array}$} & \multicolumn{2}{|c|}{$\begin{array}{l}\text { Period aftar } \\
1(121)^{+} 2(137)^{+} \\
\end{array}$} & \multirow[t]{2}{*}{$\begin{array}{l}\text { looding } \\
3(125)^{+}\end{array}$} & Fasting & \multicolumn{3}{|c|}{${ }_{1}^{\text {Porlod artar loading }}$} \\
\hline & & & $\mathrm{NH}_{0} / 100 \mathrm{ml}$ & $-\infty$ & - & & $\cdots \mu$ & fin. -. & & & $-p$ & /ain. & \\
\hline & 28.1 & 41.6 & 41.6 & 39.3 & 39.3 & 31.5 & 50.4 & 55.4 & 49.2 & 0.28 & 0.06 & 0.15 & 0.09 \\
\hline L-arginine & 16.1 & 28.8 & 26.8 & 28.8 & 27.0 & 18.1 & 35.2 & 39.7 & 34.5 & nil & 0.38 & 0.45 & 0.54 \\
\hline L-cystine & 9.0 & 8.9 & 7.7 & 8.1 & 7.6 & 10.1 & 10.2 & 10.8 & 9.8 & 0.20 & 0.46 & 0.42 & 0.42 \\
\hline L-glutemine & 52.7 & 56.9 & 56.2 & 56.2 & 60.3 & 58.9 & 68.5 & 76.7 & 72.6 & 0.58 & 1.13 & 0.98 & 0.84 \\
\hline Gycine & 26.7 & 150.6 & $\mathrm{U2} .3$ & 120.0 & 125.3 & 29.9 & 162.6 & 162.6 & 153.3 & 1.07 & 52.3 & 49.9 & 4604 \\
\hline L-bietidine & 8.8 & 20.3 & 19.0 & 27.2 & 16.1 & 9.9 & 23.8 & 24.8 & 20.7 & 0.55 & 3.87 & 3.87 & 3.55 \\
\hline L-isoleucine & 9.2 & 50.4 & 48.1 & 48.1 & 50.4 & 10.2 & 59.6 & 65.7 & 61.8 & nil & 0.21 & 0.23 & 0.21 \\
\hline I-leucine & 24.5 & 71.8 & 70.2 & 73.3 & 74.8 & 16.3 & 86.3 & 98.5 & 92.4 & 0.04 & 0.38 & 0.30 & 0.29 \\
\hline L-Lyeine & 16.4 & 56.9 & 53.4 & 50.7 & 45.2 & 18.4 & 66.4 & 71.2 & 60.3 & 0.03 & 0.49 & 0.53 & 0.47 \\
\hline L-methionine & 3.36 & 16.6 & 27.2 & 18.7 & 18.8 & 0.38 & 20.3 & 24.6 & 23.4 & 0.013 & 0.89 & 0.99 & 0.94 \\
\hline D-mothionine & nil & 17.5 & 17.5 & 16.1 & 22.8 & nill & 22.2 & 23.0 & 24.6 & nil & 8.7 & 21.1 & 10.7 \\
\hline I-phenylelenine & 9.4 & 20.9 & 19.7 & 19.4 & 18.5 & 10.6 & 24.7 & 26.9 & 23.7 & 0.07 & 0.36 & 0.45 & 0.42 \\
\hline L-proline & 26.8 & 29.6 & 27.8 & 26.1 & 27.0 & 16.5 & 34.7 & 37.0 & 33.1 & 0.04 & 0.12 & 0.12 & 0.10 \\
\hline L-serine & $\mathbf{2 . 3}$ & 22.9 & 21.9 & 23.8 & 23.8 & 16.0 & 27.2 & 31.3 & 29.8 & 0.22 & 2.98 & 3.26 & 3.21 \\
\hline L-threonine & 12.6 & 22.7 & 22.7 & 21.0 & 21.4 & 14.2 & 27.5 & 30.1 & 27.0 & 0.08 & 1.42 & 2.59 & 1.44 \\
\hline L-tryptophas & 5.9 & щ.7 & 32.0 & 12.2 & 12.4 & 6.6 & 24.2 & 16.5 & 15.3 & 0.10 & 0.35 & 0.34 & 0.34 \\
\hline L-tyrosine & 4.42 & 7.2 & 6.6 & 6.6 & 6.6 & 5.0 & 8.3 & 9.2 & 8,3 & 0.20 & 0.12 & 0.13 & 0.21 \\
\hline Lovaline & 24.8 & 59.8 & 63.3 & 65.0 & 67.5 & 27.8 & 74.4 & $\$ 8.0$ & 82.9 & 0.03 & 0.29 & 0.20 & 0.22 \\
\hline
\end{tabular}

* Blood amino acid concentrations were determined at the beginning and end of each collection period.

+ Glomerular filtration rates.

after hydrolysis. The overall precision of microbiological assays is \pm 10 per cent. Alanine and arginine are diffcult to measure with the same degree of reproducibility obtainable with the other amino acids. Aspartic and glutamic acids were also measured during these studies but because of the extremely small amounts normally present in the urine and plasma and since the infusion mixture had been rendered virtually free of both, the changes observed were considered of dubious significance and are not included. The results for cysteine/cystine have been reported arbitrarily in terms of cystine.

\section{RESULTS}

\section{Endogenous clearance and response to load}

In Table II the results of a typical experiment on subject WB are given. It will be noted that the fasting excretion or endogenous clearance of each amino acid is extremely low, indicating almost complete tubular reabsorption. With glycine and histidine somewhat less of the filtered loads, 96 and 94 per cent, respectively, were reabsorbed. In an earlier study in which the basal
TABLE III

Endogenous clearances of the individual amino acids

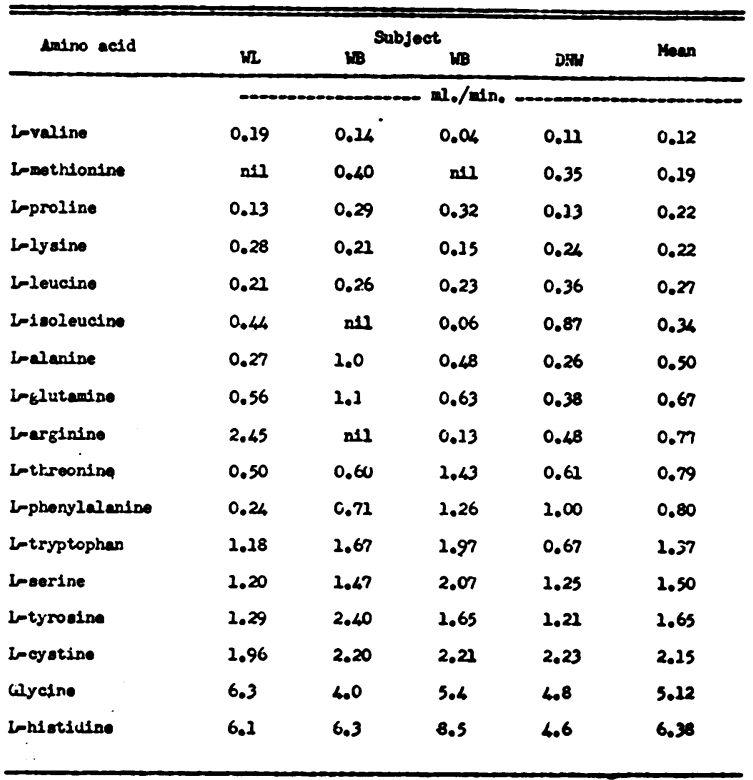


excretion of amino acids was measured in 22 normal male subjects it was found that glycine, histidine and glutamine were excreted in the largest amounts $(18,19)$. In Table III the endogenous clearances for the individual amino acids in each of the present experiments and the average values are listed. It will be noted that histidine and glycine are also cleared in the largest amounts but that the clearance of histidine exceeds that of glycine. In the case of glutamine which, as mentioned, has a large basal excretion it will be noted that the endogenous clearance is quite small.

When the blood levels and filtered loads were increased there were increases in the amounts excreted. The increase in the amount excreted varied among individual amino acids and in this particular-study tyrosine showed no significant increase. Other experiments have shown that tyrosine shares in this typical response. In any event the total amount of amino acid excreted represents only a very small part of that administered $(<4$ per cent). The most significant event, quantitatively speaking, was an increase in the amount of amino acid reabsorbed per minute. Despite definite and in some instances marked elevations in serum concentrations, only five natural amino acids were ever excreted at a rate greater than $0.5 \mathrm{mg}$. per min., glycine $>$ histidine $>$ serine $>$ threonine and on one occasion, lysine.

\section{Comparison of individual clearances}

In Table IV are listed for each subject the mean elevations in plasma concentrations obtained after amino acid loading, expressed as multiples of the fasting values, together with the grand mean for all subjects. The general pattern is as expected in that those amino acids present in the largest

TABLE IV

Elevations in concentration of the amino acids in the plasma expressed as multiples of the fasting values

\begin{tabular}{|c|c|c|c|c|c|}
\hline \multirow{2}{*}{ Amino acid } & \multirow{2}{*}{ WL } & \multicolumn{2}{|c|}{ Subject } & \multirow{2}{*}{ DEW } & \multirow{2}{*}{ Grand man } \\
\hline & & WB & WB & & \\
\hline Incyatine & 0.99 & 0.89 & 0.86 & 0.93 & 0.92 \\
\hline I-glutanine & 2.10 & 1.08 & 2.20 & 1.17 & 1.21 \\
\hline L-tyrosine & 1.76 & 1.52 & 1.35 & 1.28 & 2.48 \\
\hline Inelenise & 1.51 & 1.44 & 1.97 & 1.60 & 2.63 \\
\hline Inthreonine & 2.14 & 1.75 & 1.73 & 1.43 & 1.76 \\
\hline Inserine & 1.62 & 1.62 & 2.76 & 2.04 & 1.76 \\
\hline I-tryptophan & 2.06 & 2.04 & 1.89 & 1.62 & 1.90 \\
\hline I-proline & 2.40 & 2.85 & 2.22 & 1.40 & 2.97 \\
\hline I-arginine & 1.61 & 1.76 & 2.44 & 2.32 & 2.03 \\
\hline Inhiotidine & 2.50 & 2.05 & 2.70 & 2.09 & 2.34 \\
\hline Invaline & 2.53 & 2.58 & 2.96 & 2.93 & 2.50 \\
\hline Imphonglelanino & 4.15 & 2.09 & 2.98 & 1.88 & 2.78 \\
\hline I-2yeine & 5.00 & 3.14 & 2.89 & 2.37 & 3.35 \\
\hline Infeoleualne & 5.04 & 5.33 & 4062 & 3.75 & 4069 \\
\hline Irleuoine & 5.26 & 4098 & 4073 & 4.09 & 4.77 \\
\hline Grratne & 7.33 & 4070 & 6.49 & 5.29 & 5.95 \\
\hline Inenthionine" & 27.5 & 5.32 & 10.9 & 5.58 & 9002 \\
\hline
\end{tabular}

* The values found for methionine are of doubtful significance because of the extremely small amounts normally present in the plasma. 
TABLE $\nabla$

Clearances of amino acids during an infusion of a mixture of amino acids

\begin{tabular}{|c|c|c|c|c|c|}
\hline Amino acid & WI & $\mathrm{WB}^{S}$ & Subject & Div & Grand mear: \\
\hline L-proline & 0.58 & 0.41 & 0.48 & 0.54 & 0.50 \\
\hline L-valine & 0.70 & 0.31 & 0.47 & 0.57 & 0.51 \\
\hline Lalsoleucine & 0.62 & 0.44 & 0.56 & 1.03 & 0.66 \\
\hline Iralanine & 1.76 & 0.26 & 0.77 & 0.29 & 0.77 \\
\hline Inleucine & 0.85 & 0.45 & 0.97 & 1.09 & 0.84 \\
\hline L-arginine & 2.02 & 1.62 & 1.36 & 1.08 & 1.52 \\
\hline I-glutamine & 2.82 & 2.73 & 2.83 & 1.89 & 2.32 \\
\hline L-phenylalanine & 2.10 & 2.09 & 2.71 & 2.77 & 2.42 \\
\hline I-tyrosine & 4.00 & 1.73 & 3.19 & 1.04 & 2.49 \\
\hline Inlyaine & 2.25 & 0.97 & 4.35 & 3.70 & 2.82 \\
\hline L-tryptophan & 3.78 & 2.97 & 4.63 & 1.97 & 3.34 \\
\hline Incyatine & 4.03 & 5.21 & 7.39 & 5.81 & 5.61 \\
\hline I-methionine & 4.60 & 5.27 & 6.16 & 9.32 & 6.34 \\
\hline L-threonine & $u_{40} 7$ & 6.7 & 16.7 & 7.1 & 21.3 \\
\hline Ireerine & 21.7 & 23.7 & 34.8 & 24.3 & 22.2 \\
\hline Irbiotidine & 32.2 & 20.8 & 39.4 & 28.7 & 30.3 \\
\hline Danthionine & 49 & 57 & 47 & 56 & 52 \\
\hline Glyoine & 54 & 39 & 62 & 63 & 55 \\
\hline
\end{tabular}

amounts in the mixture are also those which exhibited greatest elevations of concentration in the plasma. In Table $\mathrm{V}$ the mean clearance achieved during the infusion of amino acids for each of the four experiments, as well as the grand mean, are listed. Glycine, D-methionine, histidine, serine, and threonine have the largest clearances under load. However, the amount of plasma cleared of a given amino acid was not predictable merely from the rise in the concentration of this amino acid which was produced in the plasma as a result of the infusion. This implies that there is a considerable variation among different amino acids in the selectivity with which these substances are reabsorbed by the renal tubules.

\section{Changes in glomerular filtration rate during amino acid infusion}

In two of the four experiments, subjects WB and DNW, a moderate increase in glomerular fil- tration rate was observed. In Table II the values obtained in subject WB are given. In the other subject (DNW) in whom an increase in GFR was also observed the values obtained during the control period were 145 and 155 , and during the amino acid infusion periods, 168,175 , and $168 \mathrm{ml}$. per min. Since there was a considerable variation from subject to subject in the plasma concentrations produced by the amino acid infusion, it is not possible to state from the present data to what extent the alterations in filtration rate influenced the amino acid clearances. Additional studies are currently in progress in an attempt to define more exactly the effect of amino acid infusions on renal hemodynamics.

\section{Clearances of $D$ - and $L$-methionine}

The clearances of the D- and L-forms of methionine were specifically compared (Table V) since an earlier study in this laboratory had shown a 
TABLE VI

Comparison of the clearances of the $D$-and $L$-forms of methionine and the effect of water diuresis (Subject, WB)

\begin{tabular}{|c|c|c|c|c|c|}
\hline & \multicolumn{5}{|c|}{ PERIODS } \\
\hline & 4 & 5 & 6 & 7 & 8 \\
\hline & \multicolumn{5}{|c|}{ 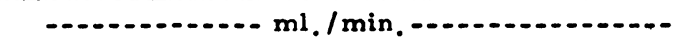 } \\
\hline Urine flow & 5.0 & 5.0 & 5.3 & 13.3 & 22.9 \\
\hline \multicolumn{6}{|l|}{ Clearance } \\
\hline D-methionine & 49. & 50. & 55. & 79. & 77. \\
\hline L-methionine & 4.6 & 4.0 & 4.3 & 3.0 & 2.8 \\
\hline
\end{tabular}

greater excretion of the D-form (20). It was noted in the present study that the clearances of the D-form were substantially higher ( 47 to 57 ml. per min.) than those of the L-form (4.6 to 9.3 ml. per min.).

In the above studies the effect of urine flow on the reabsorption of the two forms was not studied. In subject WB, a water load was administered at a time when a similar clearance study was being performed after nine days of intravenous ACTH therapy which, incidentally, did not alter the reab- sorption of amino acids in normal subjects (21). The results are reproduced in Table VI, where it will be noted that a significant increase in clearance of the D-form occurred with the onset of diuresis. These findings are similar to those which Crampton and Smyth demonstrated in the cat and which led them to conclude that the unnatural enantiomorphs of amino acids were reabsorbed passively while the natural forms were reabsorbed, at least in part, by an active mechanism (22). Dent, Senior, and Walshe have recently

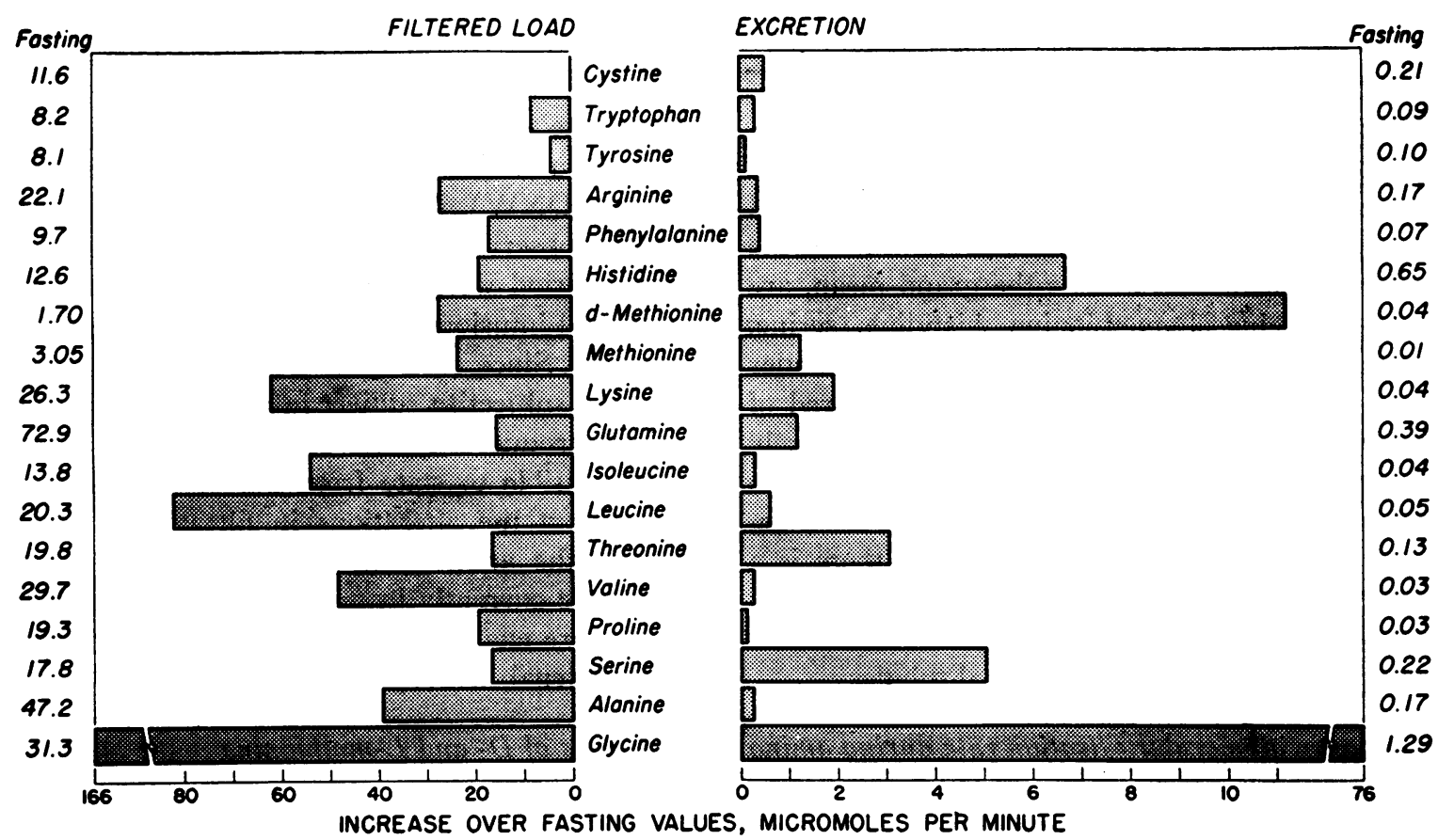

Figure 1 
shown that in normal subjects the excretion of the $\mathrm{D}$-form of cystine is much greater than that of the L-form (23).

\section{DISCUSSION}

In the fasting state the reabsorption of amino acids from the glomerular filtrate was almost complete. However, during a continuous infusion of an amino acid solution so that both the plasma level and the filtered loads are significantly increased, there was an increase in both the amounts reabsorbed and those excreted. The increase in the amounts reabsorbed far outweighed that excreted so that during the entire infusion period less than 4 per cent of the administered amino acids was excreted.

Because of this pattern of renal excretion and because of the differences in the degree to which the concentration of each amino acid was increased in the plasma, it is not possible with these data to derive a valid mathematical expression for the manner in which the individual amino acids were cleared relative to one another. The endogenous clearance, per cent excretion and/or per cent reabsorption are of dubious value as reference points.

Although the individual amino acids still cannot be compared, in the strict sense, an attempt has been made in Figure 1 to present the accumulated data in such a manner that certain general concepts concerning renal mechanisms for the excretion of amino acids can be gained. Figure 1 was prepared as follows: The columns headed "fasting" represent the mean value of the four subjects for the filtered load or excretion, respectively, of each amino acid in the fasting state. Similar mean values were then calculated for all of the experiments performed after infusion of the amino acid mixture, and horizontal bars used to represent the differences between the first (fasting) and second (load) set of mean values. It should be noted that the scale designating the amounts of amino acids excreted is 10 times larger than that referring to the amounts filtered. The individual amino acids are listed in Figure 1 in order of increasing molecular weight but no relationship of molecular weight per se to the absolute or relative amounts of amino acid excreted was apparent.
Despite significant and in some instances striking increases in the filtered loads of leucine, isoleucine, valine, alanine, arginine, proline, lysine, L-methionine, and phenylalanine, the amounts excreted remained extremely low indicating that they were reabsorbed by a mechanism or mechanisms which were still highly efficient. The data would also imply that whenever these amino acids are excreted in large amounts, it is more likely due to an impairment of the normal reabsorption mechanism than a saturation phenomenon. Chemically, this group of amino acids is heterogeneous, being composed of neutral acids of aliphatic, aromatic, heterocyclic and sulfur-containing types, as well as two basic amino acids.

The amounts of histidine, serine, threonine, and glycine excreted did rise significantly under load, indicating less complete reabsorption. These are the amino acids for which it might be anticipated that maximal reabsorptive capacities could be demonstrated and such work is currently in progress. Chemically, the group consists of three neutral monamino monocarboxylic aliphatic acids and one basic heterocyclic acid.

Earlier work in this laboratory, as well as that of other investigators, has shown that histidine $(17,18,24-26)$ and glycine $(17,18,26)$ are among those amino acids normally excreted in the largest amounts. It also should be mentioned that Eckhardt and Davidson found a proportionately larger excretion of threonine and histidine following intravenous infusion of the same amino acid solution used in this study than of any other of the amino acids studied (25). Kamin and Handler have called attention to the fact that the excretion of histidine and threonine are most frequently increased by the infusion of another single amino acid and postulated this as a possible explanation for the large excretions of these two. amino acids in a variety of normal and abnormal states (13).

Interpretation of the increases in excretion of glutamine, tyrosine and tryptophan is rendered difficult by the small increases in the amounts filtered during the load period. Glutamine may occupy a position intermediate between the first two groups of amino acids.

The increase in excretion of cystine in the absence of any increase in filtered load is noteworthy. Pitts (5, 6), Beyer and his co-workers (9), and 
Kamin and Handler (13) have all presented evidence that in the experimental animal there exists a competition between individual amino acids for reabsorption. Corroborating evidence is available in the present studies in the case of cystine. There was virtually no cystine in the mixture of amino acids which was infused and there was no significant change in the concentration of cystine in the plasma in any of the four experiments. Despite this, the average clearance of cystine during the infusion periods was $5.6 \mathrm{ml}$. per min. whereas the endogenous clearance in the four experiments were $2.2,2.2,2.2$, and $2.0 \mathrm{ml}$. per min. This indicates that one or more amino acids were reabsorbed at the expense of cystine. The results could not have been due to changes in urine flow for no correlation has been demonstrated in these experiments between urine flow and cystine clearance. Although it is conceivable that something in addition to cystine was being measured in the urine, we have no evidence for such an explanation and seriously doubt that its additive effect would be great enough to account for the results obtained. In earlier work in this laboratory it was found that homocystine, cystathionine, and homolanthionine failed to support the growth of the test organism and the activity of glutathione was always less than 20 per cent of its cysteine content (27). To what extent, if any, other amino acids were involved in such a competitive phenomenon cannot be stated on the basis of the present data, but it is a reasonable assumption that the phenomenon is not limited to cystine. The finding was actually somewhat unexpected for, in earlier studies wherein a single injection of different amino acid mixtures was administered and their excretion measured in a three-hour specimen, no significant change in cystine excretion was observed (19). However, in those studies lower concentrations of amino acids in the plasma were obtained and the urine collection period was prolonged beyond the point where acute changes would be detected. It should also be mentioned that Dent, Senior, and Walshe were unable to demonstrate in a normal subject any competition for reabsorption between cystine and lysine, ornithine, and arginine (23).

The infusion of this particular type of amino acid solution, a solution which is both hypertonic and acidic, was associated on two occasions with an increase in glomerular filtration rate. Whether this is a pharmacological effect attributable to the solution or a physiological response to the elevation in the concentrations of amino acids in the plasma remains to be determined. Other factors, such as alterations in the body fluid compartments may possibly have been operative. Pitts infused single amino acids or combinations of amino acids into dogs and observed an initial increase and subsequent decrease in glomerular filtration rate $(5,6)$. On the other hand, Wright $(10)$ and Russo (12) noted no significant effect on either filtration rate or renal blood flow with the infusion of single amino acids or combinations thereof, or when an acid hydrolysate of casein was infused. To what extent the increase in filtration rate influenced the results obtained cannot be stated. It is interesting, however, to note that the increased excretion of histidine which is found in pregnancy has been ascribed largely to the normal increase in glomerular filtration rate which occurs during most of the period of pregnancy (28).

\section{SUMMARY}

1. The renal clearances of 18 individual amino acids have been studied in three normal human subjects by the simultaneous measurement of inulin and amino acid excretion during periods of fasting as well as during the infusion of an amino acid mixture.

2. Excretion during fasting, i.e., the endogenous clearance of each amino acid measured, was extremely low, indicating that the reabsorption of amino acids from the glomerular filtrate was almost complete at the plasma levels which prevail in the fasting state.

3. During a continuous infusion of an amino acid solution, there was an increase in the amounts of amino acids reabsorbed as well as those excreted. However, even under these conditions of loading, less than 4 per cent of the administered amino acids was excreted.

4. The excretion of isoleucine, leucine, valine, proline, alanine, methionine, arginine, phenylalanine, and lysine remained small despite significant and in some instances striking elevations in plasma concentrations. Histidine, serine, glycine, and threonine were excreted in larger amounts when the plasma levels were increased. 
5. Evidence for competition between individual amino acids for tubular reabsorption was obtained in the case of cystine.

6. The clearance of the unnatural D-isomer of methionine was much higher than that of the natural, L-form. In the presence of a diuresis induced by a water load, a significant increase in clearance of the D-form occurred while that of the L-form decreased. This is taken as evidence for passive reabsorption of the $\mathrm{D}$-form.

\section{ACKNOWLEDGMENT}

The constructive comments and advice of Drs. Thomas J. Kennedy, Jr., and Robert W. Berliner are gratefully acknowledged.

\section{REFERENCES}

1. Sheffner, A. L., Kirsner, J. B., and Palmer, W. L., Studies on amino acid excretion in man. I. Amino acids in urine. J. Biol. Chem., 1948, 175, 107.

2. Doty, J. R., Reabsorption of certain amino acids and derivatives by the kidney tubules. Proc. Soc. Exper. Biol. \& Med., 1941, 46, 129.

3. Goettsch, E., Lyttle, J. D., Grim, W. M., and Dunbar, $P$. The renal amino acid clearance in the normal dog. Am. J. Physiol., 1944, 140, 688.

4. Eaton, A. G., Ferguson, F. P., and Byer, F. T., The renal reabsorption of amino acids in dogs: Valine, leucine, and isoleucine. Am. J. Physiol., 1946, 145, 491.

5. Pitts, R. F., A renal reabsorptive mechanism in the dog common to glycin and creatine. Am. J. Physiol., 1943, 140, 156.

6. Pitts, R. F., A comparison of the renal reabsorptive processes for several amino acids. Am. J. Physiol., 1944, 140, 535.

7. Ferguson, F. P., Eaton, A. G., and Ashman, J. S., Renal reabsorption of methionine in normal dogs. Proc. Soc. Exper. Biol. \& Med., 1947, 66, 582.

8. Beyer, K. H., Wright, L. D., Russo, H. F., Skeggs, H. R., and Patch, E. A., The renal clearance of essential amino acids: Tryptophane, leucine, isoleucine, and valine. Am. J. Physiol., 1946, 146, 330.

9. Beyer, K. H., Wright, L. D., Skeggs, H. R., Russo, H. F., and Shaner, G. A., Renal clearance of essential amino acids: Their competition for reabsorption by the renal tubules. Am. J. Physiol., 1947, 151, 202.

10. Wright, L. D., Russo, H. F., Skeggs, H. R., Patch, E. A., and Beyer, K. H., The renal clearance of essential amino acids: Arginine, histidine, lysine, and methionine. Am. J. Physiol., 1947, 149, 130.

11. Wright, L. D., Renal clearances of essential amino acids. Tr. New York Acad. Sc., 1948, Ser. II, 10, 271.
12. Russo, H. F., Wright, L. D., Skeggs, H. R., Tillson, E. K., and Beyer, K. H., Renal clearance of essential amino acids: Threonine and phenylalanine. Proc. Soc. Exper. Biol. \& Med., 1947, 65, 215.

13. Kamin, H., and Handler, P., Effect of infusion of single amino acids upon excretion of other amino acids. Am. J. Physiol., 1951, 164, 654.

14. Rose, W. C., Amino acid requirements of man. Federation Proc., 1949, 8, 546.

15. Doolan, P. D., Hutchin, M. E., and Harper, H. A., Unpublished observations.

16. Jonxis, J. H. P., and Huisman, T. H. J., Amino aciduria and ascorbic acid deficiency. Pediatrics, 1954, 14, 238.

17. Roe, J. H., Epstein, J. H., and Goldstein, N. P., A photometric method for the determination of inulin in plasma and urine. J. Biol. Chem., 1949, 178, 839.

18. Harper, H. A., Hutchin, M. E., and Kimmel, J. R., Concentrations of nineteen amino acids in plasma and urine of fasting normal males. Proc. Soc. Exper. Biol. \& Med., 1952, 80, 768.

19. Harper, H. A., Hutchin, M. E., Doolan, P. D., and Shreeve, W. W., Unpublished observations.

20. Kinsell, L. W., Harper, H. A., Barton, H. C., Hutchin, M. E., and Hess, J. R., Studies in methionine and sulfur metabolism. I. The fate of intravenously administered methionine in normal individuals and in patients with liver damage. $\mathrm{J}$. Clin. Invest., 1948, 27, 677.

21. Shreeve, W. W., Hutchin, M. E., Harper, H. A., Doolan, P. D., and Miller, C. D., Excretion of amino acids in nephrosis. Proc. Soc. Exper. Biol. \& Med., 1955, 88, 510.

22. Crampton, R. F., and Smyth, D. H., The excretion of the enantiomorphs of amino-acids. J. Physiol., 1953, 122, 1.

23. Dent, C. E., Senior, B., and Walshe, J. M., The pathogenesis of cystinuria. II. Polarographic studies of the metabolism of sulphur-containing amino-acids. J. Clin. Invest., 1954, 33, 1216.

24. Hier, S. W., Urinary excretion of individual amino acids on normal and low protein diets. Tr. New York Acad. Sc., 1948, Ser. II, 10, 280.

25. Eckhardt, R. D., and Davidson, C. S., Urinary excretion of amino acids following the rapid injection of a solution of amino acids in man. J. Clin. Invest., 1948, 27, 727.

26. Stein, W. H., A chromatographic investigation of the amino acid constituents of normal urine. J. Biol. Chem., 1953, 201, 45.

27. Hutchin, M. E., Harper, H. A., Margen, S., and Kinsell, L. W., Microbiological determination of cystine, cysteine, and glutathione in plasma. $\mathrm{J}$. Biol. Chem., 1950, 185, 839.

28. Page, E. W., Glendening, M. B., Dignam, W., and Harper, H. A., The causes of histidinuria in normal pregnancy. Am. J. Obst. \& Gynec., 1954, 68. 110 . 